6 Biberfeld P, Kramarsky B, Salahuddin SZ, Gallo RC. Ultrastructura characterisation of a new human B-lymphotropic DNA virus (huma herpesvirus 6 ) isolated from patients with lymphoproliferative disease. gNCI 1987;79:933-41.

7 Efstathiou S, Gompels UA, Craxton MA, Honess RW, Ward K. DNA homology between a novel human herpesvirus (HHV-6) and huma ytomegalovirus. Lancet 1988;i:63-4.

8 Ho DWT, Field PR, Cunningham AL. The rapid diagnosis of acute EpsteinBarr virus infection by the development of an indirect ELISA for specific $\operatorname{lgM}$ antibody without rheumatoid factor and specific IgG interference. fClin Microbiol 1989;27:952-8.

9 Jacobson IM, Gang DL, Schapiro RH. Epstein-Barr viral hepatitis: an unusua case and review of the literature. Am f Gastroenterol 1984;79:628-32.

10 Niederman JC, Liu CR, Kaplan MH, Brown NA. Clinical and serologica
$817-9$

. Eggers HJ. Seroconversion against human herpesvirus- 6 (and other herpesviruses) and clinical illness. Lancet 1988;ii:273-4

12 Irving WL, Cunningham AL, Keogh A, Chapman JR. Antibody to both human herpesvirus-6 and cytomegalovirus. Lancet 1988;ii:630-1.

13 Larcher C, Huemer HP, Margreiter R, Dierich MP. Serological crossreaction of human herpesvirus-6 with cytomegalovirus. Lancet 1988;ii:963-4.

14 Cohen IR, Norins LC, Julian AJ. Competition between, and effectiveness of $\operatorname{IgG}$ and $\operatorname{IgM}$ antibodies in indirect fluorescent antibody and other tests. f Immunol 1967;98:143-9.

(Accepted 27 October 1989$)$

\title{
General practitioner response to elderly patients discharged from hospital
}

\author{
E Idris Williams, Freda Fitton
}

\begin{abstract}
Objective-To determine the effect of discharge information given to general practitioners on their management of newly discharged elderly patients.

Design-A random sample of 133 elderly patients who had unplanned readmission to a district general hospital within 28 days of discharge was compared with a matched control sample of patients who were not readmitted. Information was gathered from the hospital, the patients, the carers, and the general practitioners about the information that the hospital had sent the general practitioner and the general practitioners' response to this information.
\end{abstract}

Setting-All specialties in a district general hospital.

Patients - 266 Patients aged over 65 representative in the main demographic indices of the population of elderly patients admitted to hospital.

Results-Ten weeks after discharge the doctors had received notice of discharge about 169 of the patients, but fewer than half the discharge notices were received within the first week. General practitioners were dissatisfied with the information in $\mathbf{6 0}$ cases. A general practitioner visited 174 of the patients after their discharge from hospital and three quarters of the visits took place within two weeks of the discharge. These visits were more likely to have been initiated by patients or families than by the doctor, and this was not influenced by the doctor receiving notice of the patient's discharge. Older patients and those who had carers were the most likely to be visited. Nearly half of the carers were dissatisfied with some aspect of general practitioner care, problems with home visiting being the commonest source of complaint.

Conclusions-Hospital communications to general practitioners about the discharge of elderly patients still cause concern, particularly in the time they take to arrive. Written instruction to vulnerable elderly patients asking them to inform their general practitioner of the discharge might be helpful. Carers complained of lack of support, and it is clearly important for someone (either the general practitioner or another health worker) to visit elderly people shortly after their discharge.

\section{Introduction}

As part of a study to determine reasons for early unplanned readmission of elderly patients to hospital, general practitioners' responses to patients' discharge were examined. Previous studies have been concerned about the lack of information given to general practitioners by the hospital and the poor management by general practitioners of patients' resettlement in the community. ${ }^{1-4}$ We examined both these aspects, as well as the views of patients and carers.

\section{Subjects and methods}

The total group consisted of 266 patients aged over 65 and was made up of a random sample of 133 patients readmitted within 28 days of their discharge (study group) and a matched sample of 133 patients who were not readmitted (controls). The reasons for the difference in outcome between the study and control groups and a full description of the methods have been given elsewhere. ${ }^{5}$ The group was representative of the population of elderly patients admitted to hospital in the main demographic indices.

A postal questionnaire was sent to the general practitioners of the 266 patients who took part, and we received completed questionnaires about 212 patients. When appropriate, these data were validated by information given by patients and carers. The doctors gave information about the patients' medical conditions and treatment and also about arrangements for discharge and subsequent consultations at home and at their surgeries.

\section{Results}

Problems relating to either general practitioner care or delay in information reaching general practitioners were not considered to be the principal reason for readmission in any of the 133 patients. However, the failure of general practitioners to visit patients was considered to be a contributory factor in readmission in 15 cases and lack of information to the doctor from the hospital was a contributory factor in 49 cases.

Information about notice of hospital discharge was given by general practitioners in relation to 207 patients. Ten weeks after discharge the doctors had received notice about 71 patients who were readmitted and 98 controls. No notice was received about 30 patients who were readmitted and eight controls $\left(\chi^{2}=\right.$ $15 \cdot 5, \mathrm{df}=1, \mathrm{p}=0 \cdot 001$ ). This was in the form of a brief discharge note or summary letter direct from the hospital. The hospital maintained that discharge notes were sent direct to the general practitioner in 199 cases. Only seven patients were given a discharge note to pass on to the general practitioner, and five patients/carers remembered being told by the hospital to contact their general practitioner. General practitioners were dissatisfied with the discharge information given to them by the hospital in 60 cases. They were very dissatisfied about 13 of these. Inadequate information and late notice about discharge were the most common causes of dissatisfaction. 
It was more difficult to obtain specific information about the interval between the discharge and the general practitioners' receipt of notification but information was given in relation to 126 patients. The doctors received notice within one week for 82 of the patients and within two weeks for 103 (table I).

TABLE I - Time taken for general practitioners to receive notice of their patients' discharge from hospital

\begin{tabular}{lccc}
\hline & $\begin{array}{c}\text { Patients readmitted } \\
\text { within four weeks }\end{array}$ & $\begin{array}{c}\text { Patients who were } \\
\text { not readmitted }\end{array}$ & Total \\
\hline$<1$ week & 39 & 43 & 82 \\
1-2 weeks & 5 & 16 & 21 \\
$>2$ Weeks & 11 & 12 & 23 \\
\hline Total & 55 & 71 & $126^{\star}$
\end{tabular}

$\chi^{i}=4 \cdot 03, \mathrm{df}=2, \mathrm{p}>0 \cdot 1$

${ }_{\star}$ Notice was received about 169 patients but information about timing was not available in 43 cases.

Information gathered from patients, carers, and doctors showed that by the tenth week after discharge 174 of the whole group had received a visit from a general practitioner (table II). Of the 160 people who had been visited and about whom timing information was available, 93 had a visit within the first week from either their own general practitioner or a colleague from the practice. A further 30 were visited within the second week (table III).

TABLE II-Number of patients who received a home visit from a general practitioner within 10 weeks of discharge from hospital ${ }^{\star}$

\begin{tabular}{lccc}
\hline & $\begin{array}{c}\text { Patients readmitted } \\
\text { within four weeks }\end{array}$ & $\begin{array}{c}\text { Patients who were } \\
\text { not readmitted }\end{array}$ & Total \\
\hline $\begin{array}{l}\text { Had a home visit } \\
\begin{array}{l}\text { Did not have a } \\
\text { home visit }\end{array}\end{array}$ & 92 & 82 & 174 \\
\hline Total & 36 & 50 & 86 \\
\hline
\end{tabular}

$\chi^{2}=3, \mathrm{df}=1, \mathrm{p}>0.5$

ॠInformation obtained from general practitioners, patients, and carers.

TABLE III - Time elapsing between a patient's discharge from hospital and receiving a home visit from a general practitioner ${ }^{\star}$

\begin{tabular}{lccc}
\hline & $\begin{array}{c}\text { Patients readmitted } \\
\text { within four weeks }\end{array}$ & $\begin{array}{c}\text { Patients who were } \\
\text { not readmitted }\end{array}$ & Total \\
\hline$<1$ week & 56 & 37 & 93 \\
$1-2$ weeks & 16 & 14 & 30 \\
$>2$ Weeks & 13 & 24 & 37 \\
\hline Total & 85 & 75 & 160 \\
\hline$\chi^{2}=6 \cdot 68, \mathrm{df}=2, \mathrm{p}<0 \cdot 05$. &
\end{tabular}

Visits from the doctor after discharge were far more likely to have been initiated by patients or their families than by the general practitioners themselves ( 105 compared with 57). Visits at the patient's request were more common in the control group: 45 (57\%) compared with $34(37 \%)$ of the patients who were readmitted but relatives and neighbours were more likely to have intervened on behalf of patients who were readmitted $21(23 \%)$ compared with five (6\%) controls (table IV).

TABLE IV-Home visits by general practitioners; whom they were initiated by ${ }^{\star}$

\begin{tabular}{lccr}
\hline & $\begin{array}{c}\text { Patients who were } \\
\text { readmitted within } \\
\text { four weeks }\end{array}$ & $\begin{array}{c}\text { Patients who were } \\
\text { not readmitted }\end{array}$ & Total \\
\hline $\begin{array}{l}\text { Formal carer or } \\
\quad \text { hospital }\end{array}$ & $\begin{array}{c}6(6 \%) \\
31(34 \%)\end{array}$ & $\begin{array}{c}3(4 \%) \\
26(33 \%)\end{array}$ & 97 \\
$\begin{array}{l}\text { GP } \\
\text { Patient's request }\end{array}$ & $34(37 \%)$ & $45(57 \%)$ & 79 \\
$\begin{array}{l}\text { Relation/ } \\
\text { neighbour }\end{array}$ & $21(23 \%)$ & $5(6 \%)$ & 26 \\
\hline Total & 92 & 79 & 171 \\
\hline
\end{tabular}

^There is no information on who initiated the visit in three cases.
Whether or not general practitioners had received notice of their patients' discharges appeared to have no influence on how visits were arranged. Patients, relatives, and others initiated visits in $79(66 \%)$ cases where general practitioners had received notice and 15 $(60 \%)$ cases where they had not (table V). A significant factor in relation to general practitioner follow up visits was the patient having an identified carer. Of the 211 patients who had an informal carer, $151(72 \%)$ had been visited by a general practitioner compared with only $20(48 \%)$ of the 42 patients who had no carer (table VI).

TABLE $\mathrm{V}-$ Effect of general practitioners receiving a discharge note on the initiation of a home visit ${ }^{\star}$

\begin{tabular}{lccc}
\hline & Notice received & No notice received & Total \\
\hline $\begin{array}{l}\text { Home visit initiated by } \\
\text { general practitioners }\end{array}$ & $41(34 \%)$ & $10(40 \%)$ & 51 \\
$\begin{array}{l}\text { Home visit initiated } \\
\text { by others }\end{array}$ & $79(66 \%)$ & $15(60 \%)$ & 94 \\
\hline Total & 120 & 25 & 145 \\
\hline$\chi^{2}=0.11, \mathrm{df}=1, \mathrm{p}>0.7$ & & &
\end{tabular}

$\chi^{2}=0 \cdot 11, \mathrm{df}=1, \mathrm{p}>0 \cdot 7$.

${ }^{\star}$ Information was not available about 29 cases.

TABLE VI-Number (percentage) of home visits as determined by the patient having an informal carer ${ }^{\star}$

\begin{tabular}{lccc}
\hline & Home visit & No visit & Total \\
\hline Carer & $\begin{array}{r}151(72 \%) \\
20(48 \%)\end{array}$ & $\begin{array}{r}60(28 \%) \\
22(52 \%)\end{array}$ & $\begin{array}{r}211 \\
42\end{array}$ \\
\hline Total & $171(68 \%)$ & $82(32 \%)$ & 253 \\
\hline$\chi=8 \cdot 11, \mathrm{df}=1, \mathrm{p}<0 \cdot 005$. & & &
\end{tabular}

*Table excludes patients in homes for elderly people with no informal carer.

Age seemed to influence whether patients had a home visit after discharge. Of the 38 patients aged below $70,20(53 \%)$ were visited after their return from hospital compared with $89(63 \%)$ of those aged $70-79$, and $59(74 \%)$ of those aged 80 or over $\left(\chi^{2}=5 \cdot 54, \mathrm{df}=2\right.$, $\mathrm{p}>0.05)$. Although not significant, the trend to higher levels of visiting for the oldest patients was apparent. Most patients (211) did not visit their doctor at the surgery in the first few weeks after leaving hospital.

Patients and carers were asked whether they were satisfied with the service provided by their general practitioners. Of the 219 patients who responded to this question (95 in the study group and 124 controls) 159 were satisfied. There was little difference between the study and control group. Only $108(58 \%)$ of the carers were satisfied with the general practitioners service, and again, there was little difference between the study and control patients.

Patients and carers were asked for their views about their doctors, and in these they agreed closely. Comments were recorded for 134 patients. Of the 89 patients/carers who commented on the doctor's visiting, 26 responded favourably and noted that the general practitioner called regularly without being requested. In 63 cases there were complaints about visiting which included lack of regular visiting, no follow up initiatives, and the doctor's refusal to visit housebound patients. Criticism of the doctor's clinical management was expressed in relation to 46 patients and of the doctor's manner in relation to 28 patients.

\section{Discussion}

The two groups we studied showed some significant differences in notification of discharge to general practitioners and the general practitioner's response to this information. The differences were mainly due to the early readmission of the study patients, but nevertheless are interesting. The general practitioner's frustration at having to arrange readmission probably 
contributed to the high level of dissatisfaction recorded by the general practitioners about the hospital information system. This is supported by the significantly lower numbers of discharge notices which were eventually received for patients who were readmitted. There was no significant difference between the study and control groups in whether a visit was made after discharge by the general practitioner. There was, however, a significant difference in the timing of the visit that was probably due to the need to readmit patients in the study group at an early stage. Patients in the control group requested a visit more often than patients in the study group; the reverse was true for visits requested by relatives, probably because of the more serious nature of the study group's medical conditions and the need for readmission.

The findings in relation to hospital communication and general practitioner response raised some concerns. According to ward sisters, notice of discharge was sent to general practitioners routinely for every discharged patient but after 10 weeks these had not been received for 38 of the patients for whom this information was available. The fact that half of the total group were readmitted within four weeks may have affected this figure but a notice of the first discharge should have been received. Among the control group doctors had received no communication from the hospital 10 weeks after discharge for eight of the patients. Discharge information needs to reach the doctor quickly, and the fact that this information was not communicated quickly for a high proportion of patients is disturbing. The general practitioners often commented that the receipt of the study questionnaire or an urgent request for a visit was their first indication that the patient had been discharged from hospital.

The data indicated that notification of discharge did not necessarily result in the general practitioner initiating a visit to the patient. A discharge note made little difference to the proportions of patients who were visited. In 10 cases where no discharge note was received the general practitioner initiated a visit, presumably having heard through the primary care network. General practitioners appeared to be using additional criteria in determining the need for visits after discharge, and their decision making in this respect probably needs further examination. Clearly the doctor's knowledge of the patient must be a factor, with older patients being more likely to receive a visit. In general, people who had someone to care for them were more likely to be visited by their doctor when they came out of hospital. People without identified carers are a very vulnerable group and hospitals should make very specific communication to the doctor about the discharge of this type of patient. Few patients or carers remembered being given instructions to contact their general practitioner or a discharge note to be forwarded. Written instructions to the patient asking them to contact their general practitioner might be helpful.

Although almost three quarters of the patients who took part in the study were satisfied with their doctor's care, it is disturbing that almost half of their carers were dissatisfied. This finding supports the general feeling that elderly people are less critical and have lower expectations of their doctors than those providing care, who are often younger. Criticisms focused on the general practitioner's failure to visit regularly, poor clinical management, and unsympathetic manner. Frustration was often expressed with the general practitioner's apparent lack of interest and some patients felt that they had been abandoned. This particularly applied to elderly people who were suffering from chronic conditions for which it would seem nothing more could be done. Doctors oriented towards "doing something" may indeed feel impotent in such cases and often undervalue their personal effectiveness. ${ }^{6}$ Balint pointed out that the mere presence of a doctor may be a most "potent drug." When support from the doctor was felt to be absent the morale of patients and carers in this study was clearly affected. This raises difficult professional dilemmas for general practitioners. Elderly people and their carers still have the idea that doctors are expected to visit monthly. This is clearly both impracticable and inappropriate in most circumstances. There is more home visiting of the elderly than other age groups and such support is particularly necessary in certain situations. Discharge from hospital is likely to be such a situation.

The findings reinforce the importance of early notification to the general practitioner of a patient's discharge and an early response from the practice. If possible, initial notification should be given by telephone in advance of the actual discharge. It would also be helpful if the discharge summary note could be posted first class. This is particularly important for patients in circumstances where early unplanned readmission is a possibility. Unplanned readmission most commonly occurs in those on low incomes, those who have been admitted to hospital previously, those with severe illness, those whose condition is poor (especially where confusion, immobility, and incontinence are present), those who were initially admitted by the general practitioner, and those where the carer is in poor health or has other commitments. ${ }^{5}$ Special note needs to be made of patients who do not have an identified carer.

A visit from a general practitioner or some other professional from the practice within 48 hours of an elderly person's discharge from hospital is often helpful. The patient's care needs, medication, general condition, and follow up requirements can then be checked. It is also necessary to determine whether specific advice has been given to the patient by the hospital and whether the patients and carers have a clear understanding of this.

This study was funded by a grant from the North West Regional Health Authority. A full report can be obtained from the authors.

\footnotetext{
1 Brocklehurst JC, Shergold M. Old people leaving hospital: a follow up of 200 discharged geriatric patients. Gerontologia Clinica 1969;11:115-26.

2 Sandler DA, Mitchell JRA. Interim discharge summaries: How are they best delivered to general practitioners? Br Med f 1987;295:1523-5.

3 Dover SB, Low-Beer TS. The initial hospital discharge note: send out with the patients or post? Health Trends 1984;16:48.

4 Mageean RJ. Study of "discharge communications" from hospital. $\mathrm{Br}$ Med $\mathfrak{J}$ 1986;293:1283-4.

5 Williams EI, Fitton F. Factors affecting early unplanned readmission of elderly patients to hospital. Br Med $\mathcal{F}$ 1988;297:784-7.

6 Fitton F. The cost of prescribing in general practice. Soc Sci Med 1985;21: 1097-105.

7 Balint M. The doctor, his patient, and the illness. London: Pitman Medical 1964
}

(Accepted 2 November 1989) 